\title{
Ulectomia no tratamento de impactação dentária por fibrosamento gengival em paciente infantil: relato de caso
}

Ulectomy in the treatment of gingival fibrosis dental impaction in a child patient: case report

Ulectomía en el tratamiento de la impactación dental por fibrosis gingival en un paciente infantil: reporte de caso

Amanda Borges RODRIGUES

Departamento de Odontologia, Faculdade Morgana Potrich, FAMP, 75830-000 Mineiros - GO, Brasil https://orcid.org/0000-0001-8969-3240

Marcelle DANELON

Departamento de Odontologia Preventiva e Restauradora, Faculdade de Odontologia, UNESP Univ. Estadual Paulista, 16015-050 Araçatuba - SP, Brasil Departamento de Odontologia, Universidade de Ribeirão Preto, UNAERP, 14096-900 Ribeirão Preto - SP, Brasil https://orcid.org/0000-0003-2091-649X Laura Imbriani BENTO Departamento de Odontologia, Universidade de Ribeirão Preto, UNAERP, 14096-900 Ribeirão Preto - SP, Brasil Carla Oliveira FAVRETTO

Departamento de Odontologia, Faculdade Morgana Potrich, FAMP, 75830-000 Mineiros - GO, Brasil

\begin{abstract}
Resumo
A precoce intervenção do cirurgião-dentista em casos de impacção dentária, diminui as chances de um tratamento mais complexo posteriormente, e aumentam a estética e função da cavidade oral. O trabalho tem como finalidade, apresentar a ulectomia como procedimento cirúrgico de escolha, em um caso clínico com impacção dentária por fibrose gengival. Paciente do gênero feminino, 8 anos de idade, compareceu a clínica de Odontopediatria da Faculdade Morgana Potrich - FAMP, tendo como queixa principal a ausência dos dentes da frente. Realizado o exame intra-oral constatamos que se tratava da ausência dos dentes 11 e 21 e através do exame radiográfico, foi confirmado que os dentes estavam formados $2 / 3$ da raiz completa, sendo o suficiente para erupcionarem e ocuparem seus lugares na arcada dentária, no entanto, somente a força eruptiva não era suficiente para romper a barreira fibrótica. O plano de tratamento estabelecido foi a exérese do tecido fibroso na região incisal dos dois dentes, possibilitando passagem para se posicionarem em oclusão. Desta forma, o tratamento evitou maiores transtornos e proporcionou maior qualidade de vida a paciente, devolvendo a função e estética.
\end{abstract}

Descritores: Odontopediatria; Ulectomia; Dente Impactado.

Abstract

The early intervention of the dentist surgeon in cases of dental impaction, decreases the chances of a more complex treatment later, and increases the aesthetics and function of the oral cavity. The purpose of this study is to present ulectomy as the surgical procedure of choice in a clinical case with impaction gum fibrosis. Female patient, 8 years old. attended the Pediatric Dentistry Clinic of Morgana Potrich College - FAMP, having as main complaint the absence of the front teeth. performed the intraoral exam we found that it was the absence of teeth 11 and $21 \mathrm{x}$-ray, it was confirmed that the teeth were formed $2 / 3$ of the complete root, enough to erupt and take their place in the dental arch in the However, the eruptive force alone was not sufficient to break the fibrotic barrier. The treatment plan established was the excision of fibrous tissue in the incisal region of the two teeth, allowing passage to position themselves in occlusion. Thus, the treatment avoided serious disorders and provided higher quality of life for the patient, establishing the function and aesthetics.

Descriptors: Pediatric Dentistry; Ulectomy; Impacted Tooth.

\section{Resumen}

La intervención temprana del cirujano dental en casos de impactación dental, reduce las posibilidades de un tratamiento más complejo más adelante, y aumenta la estética y la función de la cavidad oral. El propósito de este trabajo es presentar la ulectomía como el procedimiento quirúrgico de elección, en un caso clínico con impactación dental debido a fibrosis gingival. Paciente femenina, de 8 años, asistió a la clínica de Odontopediatría en la Faculdade Morgana Potrich - FAMP, teniendo como principal queja la ausencia de dientes frontales. Después del examen intraoral, descubrimos que se trataba de la ausencia de los dientes 11 y 21 y, a través del examen radiográfico, se confirmó que los dientes se formaron 2/3 de la raíz completa, siendo suficiente para erupcionar y ocupar sus lugares en el arco dental. sin embargo, la fuerza eruptiva por sí sola no fue suficiente para romper la barrera fibrótica. El plan de tratamiento establecido fue la escisión del tejido fibroso en la región incisal de ambos dientes, permitiendo el paso para posicionarse en la oclusión. De esta forma, el tratamiento evitó trastornos mayores y proporcionó una mejor calidad de vida al paciente, devolviendo la función y la estética.

Descriptores: Odontología Pediátrica; Ulectomía; Diente Impactado.

INTRODUÇÃO

Erupção dentária é considerada um processo longo e complexo, que vai desde a localização inicial dos dentes, onde estão alojados em osso, até o momento em que estão em posição funcional na cavidade bucal ${ }^{1}$. A fase em que ocorre o rompimento e esfoliação dentária pode ser influenciada por fatores gerais, como etnias, condições hereditárias, síndromes e desordens endócrinas, e fatores locais, como nível socioeconômico, mau posicionamento do germe dentário, traumatismos, perdas dentárias precoces e fibromatose ${ }^{2}$.
A fibrose gengival é uma alteração

caracterizada pelo crescimento excessivo do tecido gengival, sendo um fator bastante comum para as indicações da ulectomia ${ }^{3}$. Normalmente é causada pelo atrito dos alimentos na região edêntula, durante a mastigação ${ }^{4}$.

Além da etiologia por traumas constantes na região, como a mastigação, a fibrose gengival também pode ser causada por uso de medicação ${ }^{3}$. O tecido gengival afetado cresce de forma densa e se torna uma barreira para o dente sucessor que não consegue rompe-la e, portanto, permanece retido. Os dentes frequentemente envolvidos são os incisivos superiores ${ }^{4}$, comprometendo a estética 
do paciente, e muitas vezes, estando relacionado a problemas psicoemocionais.

Quando a via de erupção de um dente estiver bloqueada, o obstáculo deverá ser removido, no entanto o cirurgião-dentista deverá solicitar o exame radiográfico para verificar se 0 dente está, com no mínimo, 1/3 da raiz formada, o que corresponde ao estágio 7 de Nolla, pois é a partir deste estágio que 0 dente possui força eruptiva ${ }^{5}$.

Para a correta indicação da ulectomia, o profissional deve avaliar tanto o clínico quanto o radiográfico. Através do exame clínico, observar se há um aumento de volume e coloração mais pálida da gengiva, pelo aumento da camada de queratina do epitélio ${ }^{2}$, além de marcas contornadas, denotando a presença iminente do dente não irrompido ${ }^{6}$. No exame radiográfico, avaliar a rizogênese do dente permanente, se atingiu $2 / 3$ do seu estágio e se há presença de camada óssea recobrindo a coroa dentária, má formação dentária, presença de supranumerários, falta de espaço, agenesia ${ }^{2,7}$.

Esse procedimento cirúrgico, consiste na remoção parcial do tecido que reveste a região incisal ou oclusal de um dente não irrompido, com incisões elípticas, circulares ou ovais, oferecendo um caminho livre e, portanto, permitindo que o dente ocupe o seu lugar na arcada dentária ${ }^{8}$.

Dessa forma, o intuito deste trabalho é apresentar a ulectomia como opção de tratamento em um caso em que os incisivos centrais superiores estavam recobertos por uma fibrose gengival espessa, em paciente com idade escolar.

CASO CLÍNICO

Paciente do sexo feminino, 8 anos de idade, compareceu a clínica de Odontopediatria da Faculdade Morgana Potrich - FAMP, tendo como queixa principal a ausência dos dentes da frente. Feito a anamnese e o exame clínico, comprovou-se que se tratava dos dentes $11 \mathrm{e}$ 21 (Figura 1), e não havia motivo aparente para o retardo da erupção, procedeu-se com o exame radiográfico para verificar se os mesmos estavam formados.

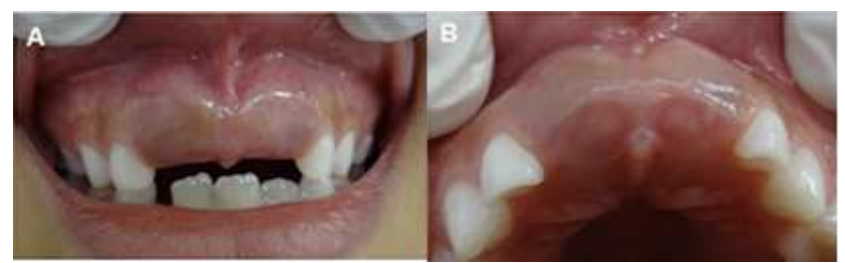

Figura 1: (A) Vista frontal da região anterior da maxila. (B) Vista oclusal da região anterior da maxila.

Com a imagem radiográfica confirmou-se que os dentes já estavam com toda a coroa e $2 / 3$ da raiz formados (Figura 2 ), correspondendo ao estágio 8 da classificação de Nolla e tendo como barreira para sua irrupção, apenas a gengiva, a qual no exame intraoral, se encontrava com uma coloração rósea pálido e consistência fibrosa na região, o que confirmou ser este o motivo dos dentes estarem retidos.

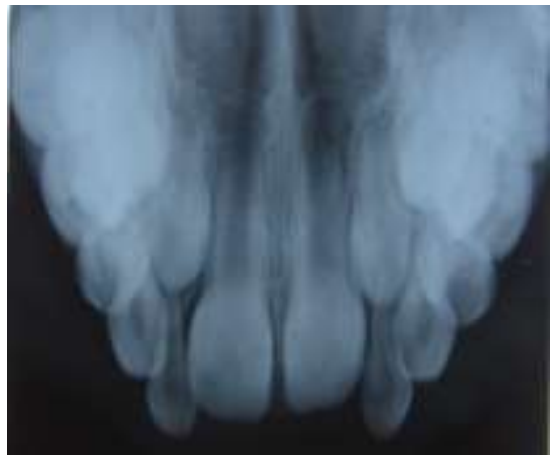

Figura 2: Exame radiográfico do tipo oclusal da maxila.

Devido à ausência de tecido ósseo e presença de uma gengiva fribrosada, optou-se pelo tratamento denominado ulectomia, que consiste na remoção da gengiva que recobre a incisal do dente para permitir um caminho desimpedido de qualquer bloqueio, possibilitando a passagem dos mesmos.

Para isso, deliberou-se a anti-sepsia bucal feita com clorexidina $0,12 \%$, por um minuto, fez-se o uso de anestesia tópica a base de lidocaína aplicada com gaze posicionada por 3 minutos na mucosa vestibular da região, seguido por anestesia infiltrativa do nervo alveolar superior anterior e nervo nasopalatino, dispondo do anestésico a base de lidocaína a $2 \%$ com epinefrina. Com o auxílio de um cabo de bisturi e uma lâmina $15 \mathrm{C}$ foi inserida na gengiva, na região incisal do dente, até encontrar resistência e procedido com uma incisão sob forma elíptica, da distal para a mesial, tanto na face vestibular como na palatina e após a exérese do tecido, evidenciou a borda incisal dos dentes em questão (Figura 3).

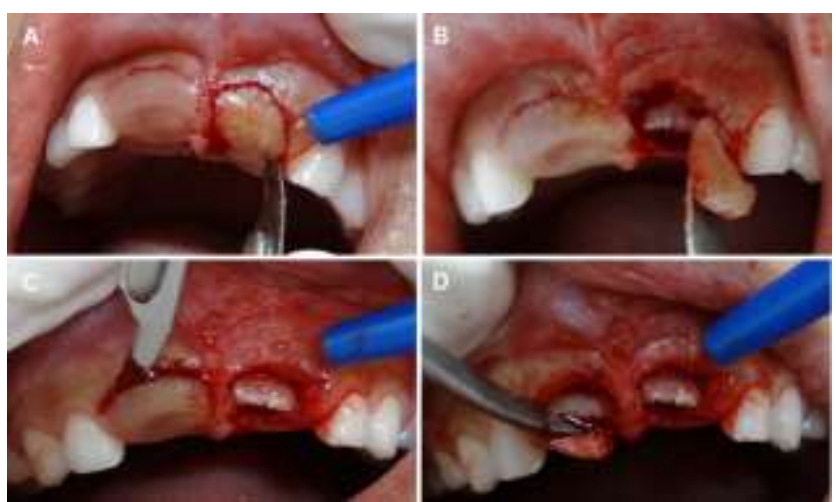

Figura 3: (A e C) Incisão tecidual do dente 11 e 21. (B e D) Descolamento do tecido gengival recobrindo o dente 21 e 11.

Finalizamos a cirurgia irrigando cuidadosamente a região com soro fisiológico e com compressas de gazes realizou-se a 
hemostasia, sem necessidade de suturas $e$ medicação. A paciente foi devidamente orientada e remarcada para acompanhamento e proservação. Após 7 dias a paciente retornou com uma excelente cicatrização e já $1 / 3$ da coroa erupcionada. Após 6 meses, observou o dente totalmente erupcionado (Figura 4).

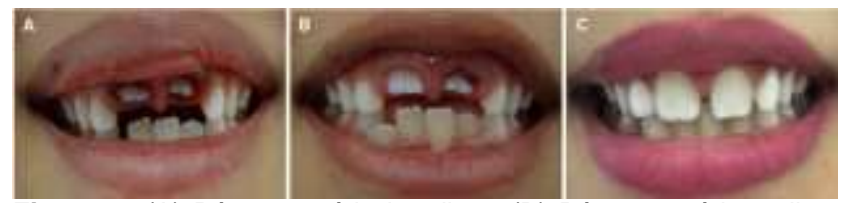

Figura 4: (A) Pós-operatório imediato. (B) Pós-operatório 7 dias. (C) Acompanhamento após 6 meses.

DISCUSSÃO

A erupção correta dos dentes, não apenas evita transtornos funcionais como, mastigação, fonética, conforto de côndilo, dores na musculação, mas também garante que não haja comprometimento da socialização do indivíduo adulto ou não ${ }^{9}$. No caso relatado, a paciente estava sendo vítima de piadas pelos colegas da escola, sentindo-se assim, constrangida e vulnerável, refletindo negativamente em seu desempenho em sala de aula e socialização como um todo. Os principais motivos que levam ao bullying, está relacionado a aparência dos dentes (47\%), gerando os insultos mais aflitivos ${ }^{10}$. Devolver a estética ao paciente, é garantir qualidade de vida, melhorando a autoestima do mesmo, frente a sociedade.

Em casos de não irrompimento de elementos dentais, o cirurgião-dentista precisará intervir com avaliação clínica, radiográfica e uma anamnese de forma criteriosa em busca de um maior número de informações para um correto diagnóstico, pois isso implicará diretamente na escolha correta do tratamento ${ }^{6}$. As características clinicas e radiográficas do caso estão de acordo com a literatura, com gengiva fibrosada de aspecto rósea-pálido e sem presença de osso recobrindo o dente ${ }^{11}$.

Em casos em que o dente se apresenta retido apenas por tecido gengival, sem envolvimento ósseo, o pós-operatório é favorável e o paciente não relata dor ou desconforto $^{12}$. A incisão pode ser feita com lâmina de bisturi, laser ou eletrocautério. A última opção destaca-se por apresentar uma hemorragia menor, favorecendo uma melhor visualização do campo cirúrgico ${ }^{11}$, no entanto a opção pela lâmina de bisturi deu-se pelo baixo custo e simplicidade na execução.

$\mathrm{Se}$ o procedimento cirúrgico - a ulectomia - for, por alguma razão, adiado, haverá sempre o risco de curvamento do ápice radicular ou de fechamento do espaço, pela inclinação dos dentes adjacentes, o que pode gerar transtornos na dentição mista resultando posteriormente em uma má oclusão, necessitando de tratamento ortodôntico para recuperação do espaço perdido ${ }^{13}$.

Vale salientar que todo planejamento deve ser realizado em comum acordo do profissional com os pais da criança, sempre thes dando informações sobre o trabalho que será feito, tranquilizando-os quanto ao procedimento cirúrgico. A ulectomia tem por vantagem, se tratar de um procedimento simples, de fácil execução, minimamente invasivo, proporcionando uma boa recuperação do paciente e resultados satisfatórios ${ }^{14}$.

CONSIDERAÇÕES FINAIS

A intervenção precoce nas alterações bucais viabiliza um tratamento de menor complexidade evitando submeter o paciente a maiores traumas, para devolver a saúde estética e funcional, portanto, a ulectomia se mostrou eficiente como escolha de intervenção em impacção dentária apenas por tecido gengival fibroso, se mostrando uma técnica simples, segura e conservadora, com excelentes resultados e pós-operatório favorável.

REFERÊNCIAS

1. Bastos JL, Peres MA, Peres KG, Barros AJ. Infant grown, development and tooth emergence patterns: a longitudinal study from birth to 6 years of age. Arch Oral Biol. 2007; 52:598-606.

2. Guedes-Pinto AC. Odontopediatria. São Paulo: Santos; 1999.

3. Lascala NT, Lascala Junior NT. Aspectos cirúrgicos na prevenção - frenectomia, bridectomia e ulectomia. In. Lascala NT. Prevenção na clínica odontológica: promoção de saúde bucal. São Paulo: Artes Médicas; 1997.

4. Guedes-Pinto AC. Odontopediatria clínica: Série EAP-APCD. São Paulo: Artes Médicas; 1998.

5. Koch G, Modeér T, Pousen S, Rasmussen P. Odontopediatria: Uma abordagem clínica. São Paulo: Santos; 1995.

6. Stuani AS, Souza AHF, Stuani AS, Stuani MBS. Solução alternativa para incisivo superior impactado. Rev Ibero-am Odontopediatr Odontol Bebê. 2004;7:335-40.

7. Duque C, Aranha AMF, Carrara CFC, Hoshi AT. Ulectomia: Relato de caso clínico. Disponível em: http://www.odontologiainfantil. com.br. Acesso 18 Jul 2020.

8. Poricelli E, Ponzoni D. Cirurgia bucal pediátrica. In: Toledo OA. Odontopediatria: Fundamentos para a prática clínica. São Paulo: Premier; 2005. 
9. Tagliaferro EPS, Guirado CG. Manutenção de espaço após perda precoce de dentes decíduos. RFO UPF. 2002;7:13-7.

10. Al-Bitar ZB, Al-Omari IK, Sonbol HN, Al-Ahmad $\mathrm{HT}$, Cunningham SJ. Bullying among Jordanian schoolchil-dren, its effects on school performance, and the contribu-tion of general physical and dentofacial features. Am J Orthod Dentofacial Orthop. 2013;144:872-78.

11. Silva FWGP, Queiroz AM, Stuani AS, Nelson Filho $\mathrm{P}$, Díaz-Serrano KV. Ojal quirúrgico (Ulectomia). Cuando y como realizarlo?: reporte de 3 casos clínicos. Acta odontol venez. 2008;46:1-7.

12. Issao M, Guedes-Pinto AC. Manual de odontopediatria. São Paulo: Pancast; 1999.

13. Cavalcante AL, Paiva LCA. Utilização da ulectomia na clínica infantil: relato de caso. Publ UEPG Ci Biol Saúde. 2006;12:39-42.

14. Poricelli E, Ponzoni D. Cirurgia bucal pediátrica. In: Toledo OA. Odontopediatria: Fundamentos para a prática clínica. São Paulo: Premier; 2005. p. 315-30.

\section{CONFLITO DE INTERESSES}

Os autores declaram não haver conflitos de interesse

\section{AUTOR PARA CORRESPONDÊNCIA}

\section{Carla Oliveira Favretto}

Faculdade Morgana Potrich - FAMP

Departamento de Odontopediatria

Endereço: Av. Antônio Carlos Paniago, S/N, Campus II Centro, Mineiros - GO, 75830-000

Telefone: (64) 99910-7494

Email: carla.favretto@gmail.com
Submetido em 27/07/2020

Aceito em 23/10/2020 